\title{
ROMPIENDO EL SISTEMA DE AUTORÍA: PRÁCTICAS CINEMATOGRÁFICAS COLABORATIVAS Y NARRATIVAS TRANSMEDIALES EN LA ERA DIGITAL
}

BREAKING AUTHORSHIP SYSTEM: COLLABORATIVE FILMMAKING PRACTICES AND TRANSMEDIA NARRATIVES IN THE DIGITAL AGE

JuANJo Balaguer PÉRez

Universidad de Granada juanjobp@correo.ugr.es

JoRDI AlBeRICH-PASCUAL

Universidad de Granada

jalberich@ugr.es

RESUMEN: El presente artículo analiza diferentes propuestas de creación cinematográfica colaborativa que rechazan la autoría única. En primer lugar, se muestra el alcance y la significación de dos agrupaciones de cineastas en ámbito español, el Colectivo Cine de Clase y el Colectivo Cine Sin Autor. Perteneciendo a distintas épocas, ambos colectivos encuentran un vínculo en su creación colaborativa, que además implica una ruptura en relación a la mitologización de la autoría única. El artículo aborda esta eliminación común de una narrativa individual en los equipos de creación audiovisual, para después centrarse tanto en su fundamentación social como en su intento de establecer nuevos modos de representación. Posteriormente, se examinan otras tipologías de audiovisual participativo, características de la era digital, que también asumen una autoría colectiva. Incorporan con frecuencia formatos, procesos y enfoques recientes de creación, entre los que destacamos las narrativas transmediales, que en ocasiones originan nuevas perspectivas sobre la autoría. Tras ofrecer una discusión sobre las aportaciones y las limitaciones que encuentra el modelo de creación colaborativa al que pertenecen los casos seleccionados, indicamos algunas contribuciones que estos enfoques de creación, especialmente las narrativas transmediales, pueden ofrecer al audiovisual colaborativo contemporáneo y a la autoría colectiva.

PalABRAS CLAVE: Autoría colectiva; creación colaborativa; cine militante; narrativa transmedial; activismo 
ABSTRACT: This article analyses different proposals of collaborative film creation that reject single authorship. Firstly, the reach and significance of two groups of filmmakers in the Spanish context, the Colectivo Cine de Clase and the Colectivo Cine Sin Autor. Belonging to different periods, both collectives find a connection in their collaborative creation, which also implies a rupture with the mythologization of single authorship. The article addresses this common removal of individual narrative in audiovisual creation teams in order to then focus on their social basis as well as on their attempt to establish new ways of representation. Then we analyse other types of participatory cinema, which is characteristic of the digital era, that also include collective authorship. They often incorporate recent creation formats, processes and approaches, among which we emphasise transmedia narratives, which, occasionally, create new perspectives on authorship. After providing a discussion on the contributions and limits of this collaborative creation model to which the selected cases belong, we mention some contributions that these creation approaches, especially transmedia narratives, can offer to contemporary participatory cinema and to collective authorship.

KEYWORDs: Collective authorship; Collaborative Creation; Militant Cinema; Transmedia Narrative; Activism

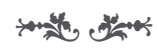

\section{INTRODUCCIÓN}

Entre las nociones que construyen el discurso fílmico, el concepto de autoría única vinculada a la labor de dirección ha sido uno de los cimientos clave para la comprensión crítica y comercial de la cinematografía (Wexman 2003). Perspectivas alternativas han dado lugar, sin embargo, a un cine minoritario que se caracteriza tanto por ser colaborativo, es decir, por limitar las jerarquías en su proceso productivo, como por su autoría colectiva, implicando así una ruptura con la concepción autoral, establecida y dominante desde hace décadas en el sistema del cine.

El concepto de autor aplicado al ámbito fílmico surgió en la primera mitad del siglo xx. Algunos teóricos, como Epstein (1926), ya habían situado al director en esa posición. Más adelante, en el texto "Naissance d'une nouvelle avantgarde: la caméra-stylo", Alexandre Astruc (1948) argumentaba la existencia de un lenguaje cinematográfico y por tanto la presencia de una autoría equiparable a la literaria, lo que sirvió de precedente a la politique des auteurs, definida por los críticos de la revista Cahiers du Cinema en la década de 1950. Esta teoría terminaría de adjudicar la autoría a la persona que ejercía la labor de dirección.

La diferencia entre lo que argumentaron los críticos de Cahiers y las nociones previas de autoría fílmica radicaba en la vinculación entre el autor y el concepto de mise-en-scène (Hayward 1996). Este permitía reconocer un cierto 
estilo en la realización de la película, que distinguía a unos autores frente a otros por su empleo de un lenguaje específicamente cinematográfico, lo que desplazaba la relevancia de intérpretes, productores o guionistas.

Además, la politique des auteurs habría sido una respuesta ante la crisis de percepción del cine por parte de ciertos sectores culturales, en contra de

Los aires elitistas de ciertos intelectuales literarios respecto al cine; el prejuicio iconofóbico respecto al cine como "medio visual"; el debate sobre la cultura de masas que veía al cine como agente de alienación política; y el tradicional antiamericanismo de la élite literaria francesa. (Stam 2000: 109)

La teoría reivindicaba por tanto un estatuto cultural propio para la cinematografía. El artículo de François Truffaut, titulado "Une certaine tendance du cinéma français" (1954), apuntala esta perspectiva. En el texto, el cineasta se posiciona contra un cine que alcanzó mucha popularidad en Francia, fundamentado en la adaptación de obras literarias de prestigio. Se establecía así una fórmula que pretendía dar crédito al cine solo en la medida en que se encontraba vinculado a esas obras. En última instancia, reforzaba su dependencia con respecto a la literatura, negaba la especificidad del cine y ahogaba su posibilidad de alcanzar una autonomía con respecto a otras expresiones artísticas. En respuesta, Truffaut exigía el reconocimiento del lenguaje cinematográfico, que debía ser expresado por cineastas, cualificados para emplear los recursos fílmicos, en lugar de por escritores. El concepto de autoría única asociado a la persona responsable de la dirección perdura desde entonces como un principio básico para la crítica cinematográfica (Sedeño 2012).

Décadas después del arraigo de la politique des auteurs, uno de sus principales teóricos, impulsor de ese cambio de paradigma y poseedor de la categoría de autor, criticaba las consecuencias de esta teoría:

Una de las herencias negativas de la Nouvelle Vague es, ciertamente, la perversión de la teoría del auteur [...]. Se transformó en un culto al autor, en lugar de un culto al trabajo del autor [...] el sistema que creamos ya no existe. Se ha convertido en una enorme ciénaga. (Godard, citado en Tirard 2002: 220)

Jean-Luc Godard se oponía así al culto excesivo hacia la figura del autor. Ciertamente, la autoría única implicaba convertir la obra fílmica en un testimonio individual, difuminando la aportación del grupo de trabajadores que también participan en la misma (Casetti 1999). Este reproche a la quizás malograda idea tuvo reflejo en la propia evolución de Godard como cineasta. Así, uno de los más reconocidos artífices de la nueva percepción crítica del cine optó durante un breve periodo por deconstruirla. En un momento y en otro, el trabajo del cineasta reflejó el contexto sociocultural en el que se encontraba.

Durante la década de 1960, la colectividad que vertebra los movimientos sociales comenzó a reflejarse en la creación fílmica. Surge "un compromiso cinematográfico que supuso el abandono de la noción de auteur de la modernidad cinematográfica por parte de diversos cineastas para materializar una prácti- 
ca fílmica colectiva y anónima que se convierta en arma política" (Monterrubio 2016: 55). En diversos países comienza a realizarse un cine militante que responde a los conflictos que tienen lugar en los diferentes contextos sociopolíticos. En España, por ejemplo, denuncia las condiciones de vida durante la dictadura, por lo que también fue un cine clandestino. En Francia, el cine militante trata de registrar los acontecimientos de Mayo del 68.

Godard, el autor, deja paso al Godard de la colectividad. Primero filma películas colectivas, como Loin du Vietnam (1967). Después, funda el Grupo Dziga Vertov junto con Jean-Pierre Gorin. El autor se diluye así en su compromiso militante, aunque regresaría al espacio, nunca derruido, de la autoría única. Gómez explica que

En cierta forma estas películas del grupo Dziga Vertov suponen un posicionamiento de Godard y [...]. Gorin, en el debate sobre la figura del autor que sacudía la teoría francesa en aquellos años. Roland Barthes y Michel Foucault desafiaron las teorías individualistas sobre la autoría. (Gómez 2018: 220-21)

El concepto ha sido objeto de reflexión por diversos autores además de Barthes (1968) y Foucault (1969), que definió el modo de funcionamiento de la funciónautor. Destacamos a Agamben (2005) y Negri (1988), que escribe sobre el arte como trabajo colectivo. También a partir de la década de 1960 se criticó desde una perspectiva estructuralista la politique des auteurs, con el argumento de que, al centrarse en el autor, eludía el análisis de cuestiones inherentes de la obra fílmica, como las estructuras sociales que rodean su producción (Hayward 1996; Wexman 2003).

La obra de Godard aúna la conquista del estatuto de autor fílmico y la ruptura con la autoría única. Entre el heterogéneo listado de prácticas cinematográficas que contrarían este sistema, se encuentra ese cine militante, pero también un cine colaborativo que incorpora a otros agentes en la realización de la obra y un cine posterior, ya en la era digital, que apuesta por la participación de los usuarios, lo que también diluye la autoría.

Este artículo aborda la ruptura del sistema de autoría única como punto en común de diversas prácticas fílmicas. Se centrará en el cine colaborativo que se desarrolló en distintos periodos, como la etapa de cine militante, y que aún tiene lugar en la actualidad. Intenta corregir las deficiencias de ese sistema, que se impuso como elemento de comprensión de la cinematografía al tiempo que ha invisibilizado otras modalidades de creación fílmica. Sin embargo, ni la creación colaborativa ni la autoría colectiva están exentas de debilidades.

Se contrastará la convivencia en la era digital de un cine colaborativo con fundamentación social con otro cine participativo, que no acoge por principio una voluntad de transformación social. Algunas de las prácticas más recientes se nutren de nuevas modalidades y procesos contemporáneos de producción. Suelen estar incluidas categorías de creación propias de la era digital que incorporan en ocasiones un diseño transmedial en su desarrollo. En esta forma narrativa, la historia fluye a través de distintos medios, que aportan elementos diferenciadores y expanden la narración (Jenkins 2006). En este sentido destacamos que, 
aunque el cine colaborativo se ha ubicado habitualmente en los márgenes de la cultura fílmica, está caracterizado por la participación, uno de los pilares básicos del conjunto de la producción cultural contemporánea en la era digital.

\section{Aspectos metodológicos}

El presente artículo tiene como objetivo analizar una selección de propuestas de cine colaborativo de autoría colectiva en el ámbito español para obtener conclusiones sobre sus aportaciones y limitaciones en la actualidad.

La primera etapa de investigación se ha basado en una revisión bibliográfica. Por un lado, se ha examinado la noción de autoría, tanto individual como colectiva. La perspectiva sobre esta cuestión se obtuvo con la consulta de textos claves, como las aportaciones de Barthes o Foucault y la mirada desde la cinematografía de Epstein, Astruc o Truffaut, así como con el estudio de trabajos académicos más recientes por parte de autores como Stam, Hayward o Sedeño. Por otro lado, se ha profundizado en las categorías de cine militante y de creación fílmica colaborativa, con la lectura de artículos de Mirizio o Berzosa y de Villanueva o Villaplana, respectivamente.

Tras esa aproximación general, reflejamos el cuestionamiento en relación a la autoría única y argumentamos la pertinencia de la creación participativa. Para ello, nos centramos en la función de representación que ejerce esta tipología fílmica. Tras una selección de propuestas colaborativas en ámbito español, como son las agrupaciones Colectivo Cine de Clase y Colectivo Cine sin Autor, realizamos un análisis particularizado de algunas de sus prácticas fílmicas. Empleamos una metodología cualitativa en el análisis y en la comparación de ambas propuestas, lo que nos permite definir sus características, e incluimos también una valoración de las condiciones materiales en las que cada colectivo desarrolla su actividad, en función del periodo que los contextualiza. Desde esta perspectiva se evalúa en qué medida el carácter de este cine queda afectado por su entorno. Una vez que se han determinado tanto efectos positivos como limitaciones del cine colaborativo de autoría colectiva, y tras comprender las posibilidades de expansión de esta tipología fílmica gracias al análisis anterior, se argumenta cómo puede desarrollarse en la época actual.

Para dar una respuesta a esta última cuestión, abordaremos la creación colaborativa propia de la era digital, vinculada a nuevos formatos y enfoques de creación contemporánea entre los que se incluyen las narrativas transmediales. Contrastamos prácticas colaborativas como la que inicia este artículo, que podemos denominar militante, y las que surgen en el entorno digital, para plantear así la aplicabilidad de elementos caracterizadores de una propuesta a otra, aprovechando el principio común que tienen en la participación.

\section{Cine militante y pRoblematización de la autoría ÚNicA}

En la década de 1960 se intensificó una práctica cinematográfica rupturista con respecto al audiovisual convencional, un cine de resistencia entendido como 
mecanismo de cambio social. Comenzaba la época del cine militante, con la labor de realizadores que, más allá de vehicular un discurso ideológico a través de su cine, percibieron su capacidad transformadora y se opusieron al sistema industrial al considerar que monopolizaba la expresión cinematográfica.

Este cine se diferenciaba de otras prácticas fílmicas con específica dimensión política, insertas en el sistema cinematográfico comercial, en que no solo trataba de representar a una determinada comunidad o denunciar su estado, sino que actuaba como catalizador: pretendía activarla para transformar sus condiciones de existencia (Aguilar 2015). Era una práctica que se presentaba también como un instrumento con voluntad contrahegemónica, es decir, de contestación al sistema de producción industrial (Galán 2012).

En un debate sobre cine militante organizado por la revista El viejo topo en 1977, los cineastas dieron diversas definiciones a este concepto. Llorenç Soler, por ejemplo, lo definía como "un cine que está al servicio de una ideología democrática", mientras que Jaime Larraín consideraba que era aquel "que se adscribe a una praxis política a través de un partido, o en general, a una causa". Joan Puig exponía que el cine militante "está realizado al margen de los canales habituales, por su clara voluntad de rechazo frente al bloqueo ideológico del cine dominante" (Mirizio 2017: 434).

Centrándonos en el caso español, el cine militante estuvo muy influido por el movimiento obrero, además de vinculado a corrientes políticas de izquierda. Estaba fundamentado en la oposición a la dictadura y mantenía una postura de rechazo hacia la cultura fílmica que esta imponía. Parte de los cineastas militantes fueron también recelosos con la Transición. Fernández y Prieto (2011) señalan un consenso que determina el periodo entre 1967 y 1982 como el momento de auge en España del cine alternativo, término que incluye tanto al cine militante como otras opciones también contrarias a la dictadura. Entre 1974 y 1977, los autores indican además la existencia de un intenso circuito de producción, distribución y exhibición de este cine, a pesar del imperativo de permanecer en la clandestinidad durante los años previos a la democracia.

La autoría plural del cine militante se estructuraba a través de la colectividad. Fueron numerosos los grupos de cineastas que se formaron durante esa etapa: el Colectivo de Cine de Madrid, la Cooperativa de Cine Alternatiu/Central del Curt, el Grup de Producció, el Equipo Imaxe, Yaiza Borges, el Equipo Penta, entre muchos otros, según expone García-Merás (2007), quien también indica que se filmaron alrededor de un centenar de películas militantes durante este periodo a pesar de la escasa infraestructura y de las pobres condiciones a las que estaban sometidos los realizadores. Hay que señalar que no todo el cine militante implicó una autoría colectiva.

Arnau explica que la aparición de colectivos en esta época tenía, en el caso español, una justificación diversa. Servían como instrumento que "cuestiona en sí mismo la lógica individualista del capitalismo" y que "representa un claro posicionamiento político contra el régimen franquista" (2013: 297). Al mismo tiempo, el anonimato estaba dirigido a evitar la represión hacia sus miembros.

La sustitución del autor por el colectivo dejaba su impronta en el lenguaje fílmico, ya no construido desde la visión unívoca de un creador. Esto conducía a 
diversos enfoques. Convivían la experimentación formal y un estilo directo, legible, defendido por aquellos para los que lo prioritario era la transmisión efectiva de su mensaje al espectador, en sintonía con su objetivo político (García-Merás 2007).

De entre las agrupaciones militantes, la que fundaron Helena Lumbreras y Mariano Lisa, el Colectivo Cine de Clase, introdujo una singularidad: la práctica de cine colaborativo. Incorporaba la participación efectiva de los sujetos a los que se filmaba, por lo que estos tuvieron capacidad de decisión sobre la obra final. Por ello, su renuncia a la autoría única se produce en tanto que su creación es colectiva - diluye las tareas de cada responsable en la generalidad del colectivo- y en la medida en que suma a otros participantes ajenos al equipo tradicional de producción, concediéndoles un reconocimiento similar.

Gracias a esta práctica colaborativa, el carácter colectivo del proyecto de Lumbreras y Lisa no hace referencia solo a los cineastas, sino también a las personas filmadas. Incluye a todos los participantes de la actividad fílmica: cineastas y sujetos que forman parte de la historia narrada.

La vocación social de este cine militante origina una aspiración por retratar de forma consensuada a los miembros de la comunidad que estructura la obra fílmica, para que se conviertan en colaboradores efectivos en el proceso de representación. Se establece una dinámica de trabajo horizontal en la que todos los participantes tienen cierta capacidad de decisión sobre la obra final. La autoría única queda cuestionada mediante esta opción metodológica, desde la que es entendida como una formulación que individualiza el relato, lo que limita una representación plural de los sujetos filmados.

Conteniendo el influjo de la militancia fílmica, este cine colaborativo trata de tener cierta repercusión en la sociedad y de ofrecer una alternativa al cine industrial. Elabora para ello una representación distinta de colectivos negativamente connotados, tanto por ese cine como por el ecosistema mediático general, ya que estos no documentan las condiciones materiales o la identidad de esas comunidades.

Cuando el colectivo en cuestión ni siquiera es objeto de representación, la creación colaborativa ofrece un espacio para contrarrestar su invisibilidad social o su marginalidad mediática. Posibilita que deje testimonio de su cultura, que sus miembros pasen de ser objetos pasivos a ser sujetos partícipes en su representación.

Por estos motivos, la creación fílmica colaborativa se identifica con una función social y un discurso emancipador. Incluso cuando el argumento de la obra no manifieste una postura crítica explícita, la propia formulación colaborativa implica ya un mecanismo de contestación. Mientras el autor deviene colectivo, comunidad, la colectividad fílmica encuentra en el cine colaborativo una singular estrategia de representación.

\section{Cine colaborativo y política de la colectividad}

Los antecedentes de la práctica fílmica colaborativa se remontan a las experiencias de Val del Omar en las misiones pedagógicas de la Segunda República 
Española o al tren cinematográfico de Medvedkin (Zavala y Leetoy 2016). Este último, que consistió en un equipo de filmación que recorrió Rusia registrando escenas de la vida obrera, dio nombre a los Grupos Medvedkin, fundados en la década de 1960 con un proceder similar.

Entre 1966 y 1969, en el marco de la iniciativa Challenge for Change del National Film Board of Canada (NFBC), un programa de documentales que trataba de dar visibilidad a zonas desfavorecidas del país, se realizó el proyecto colaborativo Fogo Process. Los habitantes de la isla de Fogo vivían en pequeñas comunidades con escasa infraestructura, limitada comunicación entre sí y diferencias religiosas. Una situación compleja que el director Colin Low retrató a través de una serie de entrevistas que después se mostraban a los participantes para que pudieran aprobar el retrato que de ellos se hacía. Esto provocó un intenso debate entre el público representado, lo que impulsó a Low a dar un paso más: ofreció a los habitantes de la isla que rodaran sus propias piezas audiovisuales para continuar el debate a partir de esas grabaciones. Fogo Process estuvo compuesto por veintiocho documentales paralelos que llegaron al gobierno, que actuó entonces para mejorar las condiciones de vida de los habitantes de la isla (Villanueva 2015).

Esta temprana experiencia señala dos características de esta tipología de cine colaborativo, aunque la primera no está siempre presente. Por un lado, su frecuente carácter documental, dado el intento de representar la realidad de determinados colectivos a través de mecanismos más efectivos que los habituales. Por otro lado, su perspectiva social, una condición vinculada a la anterior.

Definimos este cine colaborativo, en oposición con el audiovisual convencional, como una creación con metodología de trabajo más flexible, con una jerarquía menos pronunciada, con la contribución de un elevado número de individuos y con un proceso de toma de decisiones que implica su participación efectiva. Mientras que, para Villanueva (2015), la participación en el cine colaborativo tendría en sí misma un significado político, por lo que estaría vinculado al activismo, el término "colaborativo" no significa para Villaplana solo la conjunción del trabajo de varios agentes, sino "un proceso de coproducción en el que idealmente se incorporan y comparten permanentemente los cuestionamientos o desacuerdos sobre los procesos, metodologías e ideas de trabajo" (2015: 93).

Este cine colaborativo tiene siempre un pronunciado matiz político porque durante la creación se acuerda cómo se representa al colectivo, se da un papel activo al mismo y se construyen nuevos imaginarios sociales, por lo que se aspira incluso a una transformación social. Esta es la intersección donde se encuentran los cines colaborativo y militante. Sin embargo, solo en la creación colaborativa hallamos siempre una ruptura con el estatuto de autor único. Su irrenunciable carácter social se construye partiendo del rechazo a la toma individual de decisiones. Mientras que no existe una vinculación necesaria entre cine militante y cine sin autor, la creación colaborativa sí tiene carácter militante y rompe con la noción de autoría única.

La metodología de estas obras varía en función del grado de colaboración que asuma y las etapas en las que esta se incorpore. La escritura del guion puede 
ser colectiva, incluso cambiar durante la producción, para reflejar la postura de todos los participantes; el montaje puede ser abierto, contar con la aportación de todas las partes implicadas en la producción. Las decisiones se suelen tomar tras un proceso de debate en el que participan todos los agentes involucrados.

Resaltamos también su frecuente carácter pedagógico. La fundadora del Colectivo Cine de Clase sostenía que la clase obrera necesitaba del audiovisual para defender su causa, por lo que enseñaba a los participantes a emplear los medios fílmicos, lo que a su vez permitía sus aportaciones en los proyectos del Colectivo.

Como ocurría con el cine militante, la autoría colectiva marca el propio lenguaje de la creación colaborativa, que ha sido descrito con el término de "narrativa cruda" (Mateos y Sedeño 2015) por su reflejo sin artificio de aquello que se filma, en consonancia con una de las citadas posturas de los cineastas de la militancia.

Entre las obras del Colectivo Cine de Clase destaca el mediometraje $O$ todos o ninguno (1976) como ejemplo más significativo del cine colaborativo realizado por el grupo, habiendo sido asociado con los Grupos Medvedkin (Berzosa 2016). Este documental aborda el conflicto laboral que se produjo en la empresa Laforsa y que condujo a sus trabajadores a impulsar una huelga que duró más de cien días. La presentación de los cineastas mirando a cámara, acompañados por un trabajador de la fábrica, pone de manifiesto la vocación colaborativa que estructura todo el documental.

O todos o ninguno se planificó mediante sesiones de debate que contaban con la participación de los cineastas y de los obreros. Como se ha indicado, los trabajadores aprendieron a utilizar la cámara, por lo que pudieron rodar tomas que después fueron incluidas en el montaje definitivo. El documental revela así el testimonio en primera persona y consensuado de los impulsores de la huelga, mientras deja constancia de las duras condiciones de los obreros en su espacio de trabajo.

Heredero de ese colectivo militante, aunque más vehemente con la ruptura de la autoría única, encontramos en la actualidad al Colectivo Cine sin Autor (CsA). El grupo fue fundado por Gerardo Tudurí, responsable del Manifiesto del Cine sin Autor, texto que explica las singularidades de su propuesta. El Colectivo define su cine como una creación colaborativa que asume la indefinición de roles (Sedeño 2013). Por tanto, ambos grupos de cineastas se encuentran vinculados por la creación colaborativa, la autoría colectiva, la voluntad de repercusión social y la aspiración a ser una alternativa a la cinematografía convencional.

El CsA organiza encuentros en colegios, centros sociales, barrios y comunidades para hacer pedagogía audiovisual, como hicieron Lumbreras y Lisa, y enseñar materias como realización y narrativa con la finalidad de capacitar a los participantes en la creación de sus propias imágenes (Sedeño 2017). Al mismo tiempo, el CsA colabora con esas comunidades para llevar a cabo producciones fílmicas en sus espacios. Los grupos encuentran así nuevos modos de representación, tanto de sus relaciones como de sus entornos, ajenos a los propuestos por el cine industrial o por los medios de comunicación. 
El proceso de creación del CSA incluye la organización de sesiones de debate sobre guion, rodaje y edición de las películas. La escritura del guion es colectiva, lo que permite improvisación y cambios. Además, cuando se finaliza un borrador de montaje, se ofrece a la comunidad para posibilitar su modificación. La creación del CsA rompe así la jerarquía audiovisual, diluye los roles tradicionales de los equipos de producción y se basa en una dinámica de trabajo horizontal.

Ponemos como ejemplo proyectos como ¿Y ahora qué? (2015), una película realizada por quince mujeres durante un taller impartido por el CsA, o Il corpo che sogna (2015), una colaboración entre CsA y el colectivo de Femmine Difformi, en la cual se estableció un espacio de convivencia y diálogo para que el grupo de mujeres participantes tratara de deconstruir los roles y estereotipos de género.

El principio rector del CsA es la denominada sinautoría. Si "la 'política de los estudios' constituyó la producción cinematográfica en su versión de gran fábrica multinacional" (Tudurí 2017: 411), la política de los autores evolucionó a una producción centrada en el individuo. El fundador del CsA argumenta que, con el transcurso de las décadas, esa nueva política se trasladó desde el valor intelectual del autor a su valor comercial. Por este motivo, el Colectivo propone la política de la colectividad, que se traduce en que

\begin{abstract}
Abandonando todo rasgo autoral retomamos el carácter colectivo de la política de estudios (mucha gente produciendo una película) pero [...] no parte de la organización piramidal del cine sino que utiliza el cine como forma de conexión y organización social [...] el beneficio impulsor es de carácter social, político y también estético pero por la búsqueda de una propia autorrepresentación. (Tudurí 2017: 414)
\end{abstract}

Los principios de autoría colectiva, creación colaborativa y representación alternativa son compartidos por Colectivo Cine de Clase y Colectivo Cine sin Autor, como se ha señalado, a pesar de las décadas que separan sus prácticas cinematográficas. La vía acogida por ambos colectivos supone un incremento de la pluralidad en el proceso de realización fílmica, porque incluye a nuevos y diversos participantes con la convicción de que, aunque no estén en principio cualificados para constituirse como cineastas o realizadores, sí lo están para elaborar una representación propia.

\title{
4. Cine colaborativo y narRativas transmediales en LA ERA Digital
}

Deleuze señaló la posibilidad de que el cine participe en la tarea de fundación de un pueblo que falta que, para el autor francés, no es otra cosa que un pueblo por-venir: "el pueblo que falta es un devenir, se inventa, en los suburbios y los campos, o bien en los guetos, con nuevas condiciones de lucha a las que un arte necesariamente político debe contribuir" (citado en Núñez 2010: 48). Quizás fuera esa búsqueda, incitada por la comprensión de la creatividad estética como una resistencia política, según el mismo autor, la que fundara tanto la creación militante como los planteamientos colaborativos. 
Frente a ese carácter social, internet y la comunicación digital han abierto nuevos espacios para formas de participación creativa que dan lugar a otro tipo de cine colaborativo. Se consolidan fenómenos como el crowdfunding y el crowdsourcing, que se aplican además a la creación fílmica, al tiempo que el entorno comunicativo experimenta una erosión de los roles de producción y consumo, ahora más intercambiables. Como ocurre con el citado cine colectivo, aunque en principio no por su voluntad social, sino con frecuencia impulsado por nuevas dinámicas de consumo, la participación afecta a la estructura jerárquica de ciertas producciones audiovisuales. Altera la función de autor y propicia una autoría compartida. En contraste con el cine colaborativo previo, esta autoría recae en los usuarios. Como ese cine, ofrece un producto abierto, en constante proceso de modificación.

Ambas creaciones colaborativas mantienen algunos puntos en común, como la alteración de los roles de producción, la reducción de jerarquías o la autoría colectiva. Incluso podríamos entender ese primer cine colaborativo como un antecedente del crowdsourcing que sustenta al cine participativo digital, término enunciado por Jeff Howe (2006) que hace referencia a la consolidación de una red de voluntarios que colabora para la culminación de un proyecto. Además, una parte de la financiación de la citada obra O todos o ninguno (1976) provino de la donación de los trabajadores (Berzosa 2016), interesados en la terminación de la película, lo que recuerda a los usuarios que actualmente participan en campañas de crowdfunding.

A pesar de las similitudes entre los cines basados en la colaboración, lo cierto es que ni sus raíces ni sus postulados son comunes. El cine colaborativo del CsA comparte esa búsqueda de un espacio de cambio social con el cine militante. En cambio, ese otro cine colaborativo, entre cuyas obras están las producidas con la etiqueta de open source o crowdsourced, incorpora dinámicas parcialmente horizontales que no implican en principio una representación alternativa o una voluntad de transformación social. Encontramos así obras que se nutren de contenido generado por usuarios o que aprovechan la conectividad de la sociedad red para implementar prácticas de participación, como Spain in a Day (2016) en el caso español.

Más allá de esta creación compartida propia de la cultura participativa de la red, las narrativas transmediales también generan nuevas perspectivas en relación a la autoría. Si el diseño transmedial se construye mediante "transvases adaptativos o expansiones del repertorio entre las diferentes artes, medios o narrativas" (Gil 2015: 61), esta condición implicaría una creación colaborativa entre profesionales de distintos sectores (Sánchez-Mesa, Aarseth, Pratten y Scolari 2016).

Ya Jenkins argumentaba que "a medida que expandimos el acceso de la distribución masiva por la red, se modifica necesariamente nuestra comprensión de lo que significa ser autor y de la clase de autoridad que debería atribuirse a los autores" (2006: 184) y acuñaba el término de "autoría cooperativa" para referirse a aquellos autores de franquicias que facilitaban la participación de otros artistas en la construcción de la misma. 
A diferencia de ese cine colaborativo que rompía la autoría única, se formulaba en procesos de debate y negociaba las representaciones de los colaboradores, encontramos nuevas tipologías con las que no existe vínculo ni fundamentación común pero que aprovechan la red para establecer dinámicas de participación. Si bien se produce una ruptura de la autoría única, detrás no habría un cuestionamiento contundente de la misma. Tampoco propone necesariamente discursos de marcado carácter social.

Frente a una estandarización de este último cine colaborativo en ámbito internacional, Alberich-Pascual y Gómez-Pérez (2010) destacan iniciativas en el contexto de la creación iberoamericana independiente que además incorporan narrativas transmediales en su desarrollo.

Los autores destacan algunos proyectos como el titulado des(Iguales) (2015-2017), que tiene el propósito de dar visibilidad a las desigualdades en Latinoamérica mediante una narración colectiva que da voz a las personas que las sufren. La combinación de la metodología colaborativa y de la estructura transmedia permite crear un contenido social acorde con las prácticas fílmicas de los colectivos estudiados, al tiempo que optimiza su capacidad de involucrar al público gracias a la transversalidad que facilita el diseño transmedia: los cortos documentales, núcleo de la obra, se complementan con un canal de realidad aumentada, intervenciones urbanas, proyecciones públicas y un libro, entre otros materiales.

Más allá de las narrativas transmediales pero en el marco de las modalidades de creación propias de la red, mencionamos el webdoc español En la brecha (2018), una producción de Barret Cooperativa Valenciana con la participación de RTVE.es y el apoyo de la Diputació de València. Esta obra interactiva recoge el testimonio de siete mujeres acerca de la situación de desigualdad de género que sufren en su trabajo. A sus siete historias se unen narraciones de otras mujeres participantes, de manera que se introduce una dinámica colaborativa que permite a cualquier usuario grabar su testimonio e introducirlo en el webdoc junto con los demás. En este caso, aunque la colaboración se sustenta en mecanismos característicos de la era digital, tiene una fundamentación más cercana al tipo de cine colaborativo de carácter social que ha centrado este artículo.

Esta ruptura con la autoría única, elemento básico de vertebración comercial del cine, significa descartar una pieza de reconocimiento de la película, así como renunciar a un componente de articulación del discurso para la crítica y a un estímulo para la audiencia. Puede implicar además una desvalorización del trabajo de las personas dedicadas a cualquier labor tradicional del equipo de producción de una obra audiovisual.

Destacamos aquí que, tanto por su construcción como alternativa en rechazo al cine convencional como por su empleo de una metodología distinta a la del cine comercial, esta creación colaborativa se ha configurado como marginal y desvinculada de las corrientes principales. Dada su voluntad de repercusión social, se deduce que esto limita su finalidad.

El nuevo contexto de la era digital permite, en cambio, una revisión de la propuesta colaborativa teniendo en consideración esta debilidad, porque el 
auge de la cultura participativa en la red, la capacidad de difusión de internet, así como la relevancia que adquieren nuevos formatos y estrategias de creación cultural, permiten una visibilidad antes improbable para estos productos audiovisuales, y su posible salida de una periferia donde eran conocidos y consumidos solo por unos pocos.

\section{CONCLUSIONES}

El artículo ha incluido cuatro tipologías de autoría colectiva en el ámbito audiovisual. Previos a la era digital, encontramos un cine militante que abrazaba la colectividad y una propuesta que incorporaba procesos de negociación de la representación entre sus participantes, con ejemplos también dentro de esa militancia. En la actualidad, hemos señalado manifestaciones que heredan ese carácter social y otras que, por el contrario, solo incorporan la participación por la centralidad de esta noción en la producción cultural contemporánea.

Una paradoja afecta con frecuencia a las tipologías en las que la ruptura de la autoría única se basa en la búsqueda de una transformación colectiva: si se incluyeran en la vía convencional de comercialización, limitarían su carácter social, porque sus realizadores no contarían con tanta libertad para experimentar o probar nuevos métodos de producción, como la propia colaboración; sin embargo, si deciden rechazar esa vía convencional, su impacto social resulta mucho menos pronunciado porque su difusión queda mermada, por lo que la finalidad transformadora de la obra queda mitigada.

En relación a su rechazo de la autoría única señalamos que, aunque se puede hacer un análisis crítico sobre la imposición de esta en alusión a ciertas consecuencias ya citadas que pueden entenderse como negativas, por otro lado, supuso una conquista esencial al repercutir en el reconocimiento de un estatuto cultural propio para la cinematografía.

Una vez eliminada la autoría única, queda un espacio que debe ser ocupado por otro significante. Este puede ser el colectivo. Pero, siguiendo su perspectiva social y asumiendo su capacidad como alternativa, consideramos que el cine colaborativo debe atender a varias cuestiones. En primer lugar, debería evaluar su capacidad para introducirse en una dinámica comercial, lo que no significa que se vuelva convencional ni que rechace sus consideraciones éticas, pero sí que esté dotado de una mayor capacidad de influencia y por tanto se acerque a su finalidad social. En segundo lugar, la alternativa de la autoría colectiva debe ser siempre compatible con el reconocimiento a la labor del equipo de profesionales que forman parte del proyecto.

Con respecto al primer punto, el cine colaborativo ha esquivado las categorías de una industria especializada, jerarquizada y regulada para lograr una mayor libertad creativa que permite asumir renuncias, como el autor único o la incorporación de colaboradores no formados en materia audiovisual. Reconoce la diversidad cultural, da visibilidad a comunidades escasamente representadas y crea espacios de reflexión crítica. Pero la creación fílmica colaborativa debe ahondar en su perspectiva social, en el sentido de ampliar su capacidad de in- 
fluencia. Para ello, debe tratar de salir de los márgenes culturales tan estrechos en los que se encuentra.

En relación a la segunda idea, añadimos que el valor de la autoría se fundamentaba en la capacidad de la persona que la ostentase para aprovechar el medio cinematográfico gracias a su conocimiento y experiencia. Si bien la aportación del colectivo es positiva, probablemente no conducirá a un ejercicio fílmico tan estimulante como el que pueda ofrecer un profesional del medio y además puede dificultar la viabilidad del proyecto. La fórmula colaborativa atiende a una visión más plural, pero puede implicar la carencia de ciertas pautas encaminadas a la materialización de un valor estético o narrativo.

En la etapa de cine militante en el ámbito español, la creación situada en los márgenes respondía, entre otros motivos, a una necesidad ante el riesgo evidente de los cineastas por oponerse a la dictadura. Distinguimos entre el cine colaborativo en aquel periodo y otro de las mismas características en la época actual.

El contraste de la creación colaborativa en ambas épocas nos ayuda a reflexionar sobre la adaptación de estas prácticas al entorno actual. Este permite a sus creadores aspirar a una mayor difusión de sus obras e incrementar su repercusión. Favorecería su crecimiento, al menos en lo que se refiere a la capacidad de la red. Resulta pertinente, por tanto, encontrar fórmulas que hagan viable la inserción de este cine alternativo, de destacado valor cultural y social, en un ámbito comercial sin que por ello se reduzca su identidad diferenciadora.

Teniendo en cuenta algunos de los ejemplos citados de creación colaborativa en el entorno digital, apostamos por una visión renovada de este cine desde las narrativas transmediales y el webdoc. Esto permite la adopción de la colaboración, al tiempo que aprovecha las singularidades de diversas plataformas. La difusión que permite el entorno web facilita además una mayor visibilidad para estas obras que, aunque quizás no entrarían en el marco de la comercialización cinematográfica tradicional, pueden sumarse a los mecanismos de difusión de estas recientes tipologías de creación audiovisual. En este sentido, hay que señalar que la transmedialidad ya está presente en un amplio rango de obras audiovisuales que abarca desde la experimentación independiente hasta el cine integrado en la industria convencional.

Asimismo, si bien en proyectos del ámbito español como En la brecha (2018) se diluye la autoría única en la medida en que los usuarios -que en este caso también son sujetos activos de su representación- pueden aportar contenido propio, también se mantiene el reconocimiento a los impulsores de la obra, con una separación de roles propia del sistema audiovisual tradicional. Se elude así este inconveniente que se ha señalado en relación a la autoría colectiva.

\section{OBRAS CITADAS}

Agamben, Giorgio (2005): Profanaciones. Barcelona, Anagrama.

Aguilar, Gonzalo (2015): Más allá del pueblo. Imágenes, indicios y políticas del cine. México D. F., Fondo de Cultura Económica. 
Alberich-Pascual, Jordi; Gómez-Pérez, Francisco (2016): "Exploraciones transmedia en la creación cinematográfica colaborativa iberoamericana contemporánea", Artnodes, n. ${ }^{\circ} 18$, pp. 28-36.

Arnau, Roberto (2013): "Los colectivos cinematográficos en la España tardofranquista: militancias, transgresiones y resistencias", Doc On-line, n. ${ }^{\circ} 15$, pp. 293-318.

Astruc. Alexandre (1948): "Nacimiento de una nueva vanguardia: la 'Caméra-stylo'". En Joaquín Romaguera y Homero Alsina (eds.): Textos y Manifiestos del Cine. Madrid, Cátedra, pp. 219-224.

Barthes, Roland (1968): "La muerte del autor". En: El susurro del lenguaje. Más allá de la palabra y de la escritura. Barcelona, Paidós, pp. 65-72.

Berzosa, Alberto (2016): "Aproximación a un cine proletario español durante el tardofranquismo y la Transición", Historia, Trabajo y Sociedad, n. ${ }^{\circ}$, pp. 11-34.

Casetti, Francesco (1999): Theories of cinema, 1945-1990. Austin, University of Texas Press.

Epstein, Jean (1926): "A propósito de algunas condiciones de la fotogenia". En Joaquín Romaguera y Homero Alsina (eds.): Textos y Manifiestos del Cine. Madrid, Cátedra, pp. 335-340.

Fernández, Miguel; Prieto, Xosé (2011): "Film workshops in Spain: Oppositional Practices, Alternative Film Cultures and the Transition to Democracy", Studies in European Cinema, vol. 8, n. ${ }^{\circ} 3$, pp. 227-242.

Foucault, Michel (1969): “Qué es un autor?". En: Obras esenciales. Barcelona, Paidós Ibérica, pp. 291-318.

Galán, Marta (2012): "Cine militante y videoactivismo. Los discursos audiovisuales de los movimientos sociales", Revista Comunicación, vol. 1, n. 10, pp. 1091-1102.

García-Merás, Lydia (2007): "El cine de la disidencia. La producción militante antifranquista (1967-1981)", Desacuerdos. Sobre arte, políticas y esfera pública en el Estado español, vol. 4, pp. 16-44.

Gil, Antonio J. (2015): "Narrativa aumentada", 1616: Anuario de Literatura Comparada, n. 5, pp. 45-74.

Gómez, Iván (2018): "La revolución ausente. Fantasmas y ecos de Mayo del 68 en el cine documental de Jean-Luc Godard y el grupo Dziga Vertov", Fotocinema. Revista científica de cine y fotografía, n. ${ }^{\circ} 17$.

Hayward, Susan (1996): Cinema Studies. The Key Concepts. Nueva York, Routledge.

Howe, Jeff (2006): "The Rise of Crowdsourcing", WIRED Magazine. Accesible en <https:// www.wired.com/2006/06/crowds/> [última visita: 8.1.2019].

Jenkins, Henry (2006): Convergence Culture. La cultura de la convergencia de los medios de comunicación. Barcelona, Paidós.

Mateos, Concepción; Sedeño, Ana (2015): "Videoactivismo y autoría colectiva". En Francisco Sierra y David Montero (eds.): Videoactivismo y movimientos sociales. Teoría y praxis de las multitudes conectadas. Barcelona, Gedisa, pp. 298-232.

Mirizio, Annalisa (2017): "El anacronismo visual en el cine militante de Helena Lumbreras. Notas a propósito de la influencia de Pasolini y Zavattini", Journal of Spanish Cultural Studies, vol. 18, n. ${ }^{\circ}$, pp. 425-441.

Monterrubio, Lourdes (2016): "Del cinema militant al ciné-essai. Letter to Jane de Jean-Luc Godard y Jean-Pierre Gorin", L'Atalante. Revista de estudios cinematográficos, vol. 22, pp. 55-66. 
Negri, Toni (1988): Arte y multitud: ocho cartas. Madrid, Trotta.

Núñez, Amanda (2010): "Gilles Deleuze. La ontología menor: de la política a la estética", Revista de Estudios Sociales, n. ${ }^{\circ}$ 35, pp. 41-52.

Sánchez-Mesa, Domingo; Aarseth, Espen; Pratten, Robert; Scolari, Carlos A. (2016): "Transmedia (Storytelling?): a polyphonic critical review", Artnodes, n. ${ }^{\circ} 18$, pp. 8-19.

Sedeño, Ana María (2012): "Cine social y autoría colectiva: prácticas de cine sin autor en España", Razón y Palabra, vol. 17, n. 80.

- (2013): "Cine sin autor como pedagogía crítica audiovisual. Bases teóricas, antecedentes y postura crítica", Communication Papers. Media Literacy \& Gender Studies, n. 2 , pp. 91-97.

— (2017): "Artivismo, activismo y sinautoría audiovisual: el caso del Colectivo Cine sin Autor (CsA)", Kamchatka. Revista de análisis cultural, vol. 9, pp. 431-442.

Stam, Robert (2000): Teorías del cine. Una introducción. Barcelona, Paidós.

Tirard, Laurent (2002): Lecciones de cine. Barcelona, Paidós Ibérica.

Truffaut, François (1954): "Una cierta tendencia del cine francés". En Joaquín Romaguera y Homero Alsina (eds.): Textos y Manifiestos del Cine. Madrid, Cátedra, pp. 225-252.

Tudurí, Gerardo (2017): "Escritos en torno a Cine sin Autor", Kamchatka. Revista de análisis cultural, vol. 9, pp. 397-430.

Villanueva, Sergio (2015): "Prácticas colaborativas en el documental contemporáneo: propuesta de análisis y revisión del modo participativo en la Teoría del Documental", L'Atalante. Revista de estudios cinematográficos, vol. 20, pp. 116-123.

Villaplana, Virginia (2015): "Cine colaborativo. Discursos, prácticas y multiplataforma digitales. Hacia una diversificación de formatos transmedia participativos en el Espacio Digital Europeo", Fonseca, Journal of Communication, n. ${ }^{\circ} 11$, pp. 88-117.

Wexman, Virginia W. (ed.). (2003): Film and authorship. New Brunswick, Rutgers University Press.

Zavala, Diego; Leetoy, Salvador (2016): "Documental participativo como herramienta de agencia cultural: El Salto, un caso de estudio", IC-Revista Científica de Información y Comunicación, vol. 13, pp. 235-261. 